\title{
Life cycle assessment of biofuel production from microalgae cultivated in anaerobic digested wastewater
}

\author{
Gang $\mathrm{Li}^{1}$, Zhitao $\mathrm{Lu}^{1}$, J iang Zhang ${ }^{1}$, Huan $\mathrm{Li}^{2,3,4}$, Yuguang Zhou ${ }^{2,3,4}$, \\ Ali Mohammed Ibrahim Zayan ${ }^{5}$, Zhigang Huang ${ }^{1 *}$ \\ (1. School of Material Science and Mechanical Engineering, Beijing Technology and Business University, Beijing 100048, China; \\ 2. Bioenergy and Environment Science \& Technology Laboratory, College of Engineering, China Agricultural University, Beijing 100083, \\ China; 3. Key Laboratory of Clean Production and Utilization of Renewable Energy, Ministry of Agriculture and Rural Affairs, Beijing \\ 100083, China; 4. National Center for International Research of BioEnergy Science and Technology, Ministry of Science and Technology, \\ Beijing 100083, China; 5. Department of Agricultural Engineering, Faculty of Agriculture, Omdurman Islamic University, Omdurman
} Province, Khartoum State, Sudan)

\begin{abstract}
The whole process of biofuel production from Desmodesmus sp. EJ 8-10 cultivated in anaerobic digested wastewater (ADW) under the optimal temperature was evaluated by using the method of Life Cycle Assessment (LCA). The energy efficiency and environment emissions were under considerable for the corresponding parametric study. The functional unit was $1 \mathrm{~kg}$ microalgae. It was concluded that the harvest stage was responsible for the main energy consumption during the microalgal whole pyrolysis process. The energy conversion efficiency of the whole process was larger than 1 , which indicated that the process was profitable. The environmental impact of the whole process was $1165.67 \mathrm{mPE}_{\mathrm{T} 2000}$, among which the primary impact on the environment was eutrophication that accounts for $57.36 \%$, followed by photochemical ozone synthesis (22.56\%), acidification (17.36\%); and global warming (2.73\%), respectively.
\end{abstract}

Keywords: microalgae, fast pyrolysis, life cycle assessment (LCA), anaerobic digested wastewater (ADW), biofuel production DOI: $10.25165 /$ j.ijabe.20201301.4178

Citation: Li G, Lu Z T, Zhang J, Li H, Zhou Y G, Zayan A M I, et al. Life cycle assessment of biofuel production from microalgae cultivated in anaerobic digested wastewater. Int J Agric \& Biol Eng, 2020; 13(1): 241-246.

\section{Introduction}

Microalgae, known as new sources of biofuel production, have features such as extensive distribution, wide adaptability, rapid growth and high lipid content ${ }^{[1,2]}$. Microalgae can grow in different kinds of wastewater, which reduces the cost of microalgae cultivation and mitigates pollution ${ }^{[3,4]}$. Anaerobic digested wastewater (ADW) comprises quantities of nitrogen, phosphorus, potassium, amino acids, vitamins, protein, carbohydrates, and other substances that can promote the growth and development of microalgae ${ }^{[5-7]}$. Conducing ADW to cultivate microalgae not only benefits wastewater disposal but also effectively lowers the cost of algae production.

During the process of biomass gasification, liquefaction and combustion, biomass pyrolysis technology is indispensable for converting biomass to liquid fuel or other valuable chemical products $^{[8-10]}$. Recently, many studies have focused on the

\section{Received date: 2019-03-14 Accepted date: 2019-10-28}

Biographies: Gang Li, PhD, Associate Professor, research interest: biomass engineering, agricultural product processing engineering, Email: ligang@ btbu.edu.cn; Zhitao Lu, Master student, research interest: bioenergy clean utilization, Email: luzztao@163.com; Jiang Zhang, Master student, research interest: bioenergy engineering, Email: zjiang818@163.com; Huan Li, PhD Candidate, research interest: biomass engineering, Email: huanli828@sina.com; Yuguang Zhou, $\mathrm{PhD}$, Associate Professor, research interest: biomass engineering, Email: zhouyg@cau.edu.cn; Ali Mohammed Ibrahim Zayan, PhD, Assistant Professor, research interest: biomass conversion, Email: zayanali903@gmail.com.

*Corresponding author: Zhigang Huang, $\mathrm{PhD}$, Professor, research interest: agricultural product processing engineering. School of Material Science and Mechanical Engineering, Beijing Technology and Business University, Beijing 100048, China. Tel: +86-10-68985249, Email: huangzg@btbu.edu.cn. potential of biofuel production from microalgae cultivated in wastewater ${ }^{[11-14]}$. This approach is recognized as a cost-effective way for better waste remediation, lowering the environmental influence of biofuel production ${ }^{[15]}$. However, the energy needed, the conversion efficiency, and the degree of environmental impact during the entire process are still unknown and need to be evaluated.

As a well-established scientific framework and methodology, a life cycle assessment (LCA) aims to both evaluate the energy consumption and environmental influence of a product over its whole life cycle and identify the main sources of pollution ${ }^{[16,17]}$. As shown in Figure 1, the analytical procedures of an LCA mainly consist of the objective and scope definition, inventory analysis, results interpretation and assessment improvement ${ }^{[18,19]}$. Indeed, LCA could be accomplished by compiling a comprehensive inventory of inputs, such as raw materials, water and electricity, and quantifying the outputs, such as products, emissions and by-products, with the potential environmental impact associated with the whole process ${ }^{[20,21]}$.

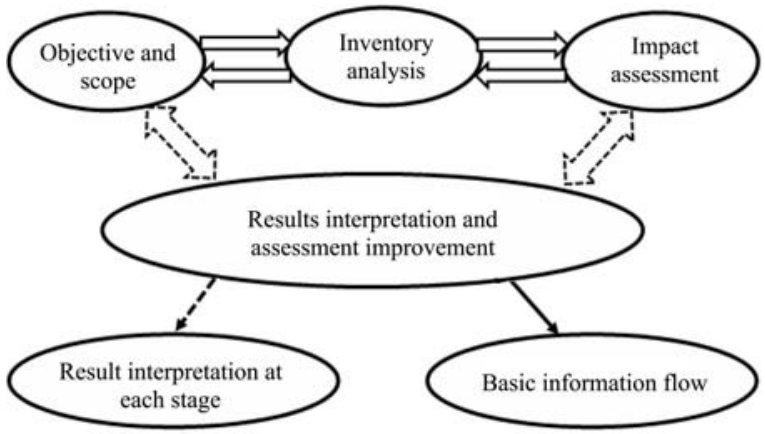

Figure 1 Phases of life cycle assessment defined by ISO 14040 
In this study, LCA was employed to evaluate the energy conversion efficiency and potential environmental impacts associated with the process of microalgae fast pyrolysis for biofuel production based on ADW cultivation. The specific energy input was comprised of the main energy consumption, the energy output and conversion efficiency, the categories of environmental impact and the primary contribution substances.

\section{Research objective and life cycle system boundary}

\subsection{Research objective}

The research objective of this study was the pyrolysis process of Desmodesmus sp. EJ 8-10. According to previous research results, the optimum pyrolysis temperature of EJ 8-10 was about $600^{\circ} \mathrm{C}^{[14]}$. This study used $1 \mathrm{~kg}$ Desmodesmus sp. EJ 8-10 as the functional unit, and the pyrolysis process of microalgae at the optimum temperature was comprehensively evaluated, including the energy efficiency analysis and environmental impact potential.

\subsection{Life cycle system boundary}

The life cycle system boundary of Desmodesmus sp. EJ 8-10 pyrolysis process was mainly defined by three stages: the cultivation stage, harvest stage and pyrolysis stage. The following assumptions and simplifications were made in the study of Desmodesmus sp. EJ 8-10 pyrolysis process using the LCA technology:

(1) This study focused on analyzing the cultivation, harvest and pyrolysis of microalgae, ignoring the depreciation and loss of centrifuge, pyrolysis and other equipment during the process;

(2) The environmental impact generated by the growth process of microalgae was excluded;

(3) The pollutants generated by each link of the system were directly discharged into the environment without post-treatment or reuse;

(4) The energy consumption of the temperature control equipment was ignored because the environmental temperature was relatively consistent with the growth temperature of microalgae.

\section{Environmental impact assessment}

According to the basic principles and framework of life cycle analysis proposed by ISO $14040^{[22]}$, the entire research process consisted of four parts: research objective and scope definition, inventory analysis, impact assessment and results interpretation.

\subsection{Inventory analysis}

\subsubsection{Cultivation stage}

In this study, the laboratory cultivation of Desmodesmus sp. EJ 8-10 mainly included three processes: the sterilization of the ADW $\left(121^{\circ} \mathrm{C}\right.$ for $\left.20 \mathrm{~min}\right)$, the inoculation in the clean bench and the 14-day cultivation on the culture shelf. The characteristics of ADW before and after sterilization were shown in Table 1. The main energy consumption includes the electricity consumption of the autoclave, the clean bench and the plant light source on the culture shelf.

Table 1 Characteristics of the ADW

\begin{tabular}{ccc}
\hline Items & $\begin{array}{c}\text { ADW before } \\
\text { sterilization } / \mathrm{mg} \cdot \mathrm{L}^{-1}\end{array}$ & $\begin{array}{c}\text { ADW after } \\
\text { sterilization } / \mathrm{mg} \cdot \mathrm{L}^{-1}\end{array}$ \\
\hline $\mathrm{NH}_{4}{ }^{+}-\mathrm{N}$ & 1490.47 & 1056.27 \\
$\mathrm{PO}_{4}{ }^{3-}$ & 33.39 & 37.16 \\
$\mathrm{COD}$ & 2820 & 2950 \\
\hline
\end{tabular}

In this experiment, a $5 \mathrm{~L}$ Erlenmeyer flask with $3 \mathrm{~L}$ medium was used, and the biomass obtained after 14 days of cultivation was $0.646 \mathrm{~g} / \mathrm{L}$. Due to the limited capacity of the autoclave, only an $8 \mathrm{~L}$ culture medium could be processed once, and 194 sterilization times were needed to obtain $1 \mathrm{~kg}$ EJ 8-10, which consumed 200.5 $\mathrm{kW} \cdot \mathrm{h}$ during the process. The inoculation time was $10 \mathrm{~min}$, and since only 105 -L triangular bottles could be inoculated each time, 52 inoculation times were needed to obtain $1 \mathrm{~kg}$ EJ 8-10, for a total of $3.5 \mathrm{~kW} \cdot \mathrm{h}$. With a day/night ratio of $14 \mathrm{~h} / 10 \mathrm{~h}$ during the 14 days cultivation, $28.2 \mathrm{~kW} \cdot \mathrm{h}$ was needed to provide the light source.

The energy that required to produce electricity per $\mathrm{kW} \cdot \mathrm{h}$ is considered as $8.02 \mathrm{MJ}$, and the main pollutants produced are $\mathrm{CO}_{2}$, $725.90 \mathrm{~g} ; \mathrm{CO}, 0.23 \mathrm{~g} ; \mathrm{CH}_{4}, 1.80 \mathrm{~g} ; \mathrm{NO}_{\mathrm{x}}, 1.12 \mathrm{~g}$; particulate matter $\left(\mathrm{PM}_{10}\right), 0.07 \mathrm{~g} ; \mathrm{SO}_{2}, 1.14 \mathrm{~g}$; and volatile organic compounds (VOC), $0.04 \mathrm{~g}^{[23]}$. Table 2 shows the energy consumption and various emissions during the cultivation of $1 \mathrm{~kg}$ Desmodesmus sp. EJ 8-10.

Table 2 Inventory analysis of Desmodesmus sp. cultivation, harvest and pyrolysis process

\begin{tabular}{ccccc}
\hline & & Cultivation & Harvest & Pyrolysis \\
\hline $\begin{array}{c}\text { Energy } \\
\text { consumption }\end{array}$ & Electricity/kW'h & $232.2^{\mathrm{a}}$ & $1226.4^{\mathrm{c}}$ & $722.2^{\mathrm{e}}$ \\
\hline \multirow{4}{*}{ Energy needed/MJ } & $1862.2^{\mathrm{b}}$ & $9835.7^{\mathrm{d}}$ & $5792^{\mathrm{f}}$ \\
\hline $\mathrm{CO}_{2} / \mathrm{g}$ & 168554 & 890243.8 & 524245 \\
& $\mathrm{CO} / \mathrm{g}$ & 53.4 & 282.1 & 166.1 \\
& $\mathrm{CH}_{4} / \mathrm{g}$ & 418 & 2207.5 & 1300 \\
$\mathrm{NO}_{\mathrm{x}} / \mathrm{g}$ & 260.1 & 1373.6 & 808.9 \\
& $\mathrm{SO}_{2} / \mathrm{g}$ & 264.7 & 1398.1 & 823.3 \\
& $\mathrm{PM}_{10} / \mathrm{g}$ & 16.3 & 85.9 & 50.6 \\
& $\mathrm{VOC}^{2} \mathrm{~g}$ & 9.3 & 49.1 & 28.9 \\
\hline
\end{tabular}

Note: ${ }^{\text {a: }}$ The sum of the electrical energy consumed during Desmodesmus $\mathrm{sp}$ cultivation including the sterilization of the medium, the inoculation in clean bench and the cultivation on the culture shelf for $14 \mathrm{~d}$; ${ }^{\text {b: }}$ Converting the sum of electrical energy consumed during Desmodesmus sp. cultivation to the energy required to produce electricity per $\mathrm{kW} \cdot \mathrm{h} ;{ }^{\mathrm{c}}$ : The sum of electrical energy consumed during the harvest of Desmodesmus sp. including the energy consumed by centrifugation and freeze drying; ${ }^{\mathrm{d}}$ : Converting the sum of the electricity consumed during the harvest of Desmodesmus sp. to the energy required to produce electricity per $\mathrm{kW} \cdot \mathrm{h} ;{ }^{\mathrm{e}}$ : The sum of electricity consumed in the pyrolysis process of Desmodesmus sp.; ${ }^{\mathrm{f}}$ Converting the sum of the electricity consumed during the pyrolysis process of Desmodesmus sp. to the energy required to produce electricity per $\mathrm{kW} \cdot \mathrm{h}$.

\subsubsection{Harvest stage}

After the cultivation of $14 \mathrm{~d}$, the samples were placed in $5 \mathrm{~L}$ triangular flasks and then stood for more than $24 \mathrm{~h}$ for the sedimentation of microalgal cells. A large amount of supernatant liquor was drawn out with a rubber tube until the liquid was reduced to $1 \mathrm{~L}$. The environmental pollution of the upper culture medium was not considered in this process. This process could reduce the energy consumption of centrifugation effectively.

Due to the limited volume of the centrifuge, only $1.5 \mathrm{~L}$ of samples could be centrifuged each time (6000 r/min, $10 \mathrm{~min})$. Totally, the collection of $1 \mathrm{~kg}$ EJ 8-10 required 1032 centrifugations, which consumed about $1135.2 \mathrm{~kW} \cdot \mathrm{h}$. The centrifuged EJ8-10 suspension was freeze-dried for $48 \mathrm{~h}$ and collected as the raw material for subsequent pyrolysis, the energy consumption to obtain $1 \mathrm{~kg}$ Desmodesmus sp. EJ 8-10 was 91.2 $\mathrm{kW} \cdot \mathrm{h}$ during the freeze-drying process. Table 2 shows the energy consumed during the harvest stage of Desmodesmus sp. EJ 8-10 was $1226.4 \mathrm{~kW} \cdot \mathrm{h}$, and the main atmospheric emissions were $\mathrm{CO}_{2}$, $\mathrm{CH}_{4}, \mathrm{NO}_{\mathrm{x}}$ and $\mathrm{SO}_{2}$.

\subsubsection{Pyrolysis stage}

The pyrolysis stage of Desmodesmus sp. EJ 8-10 included pyrolysis in a pyrolyzer and real-time analysis of the pyrolysis 
products. According to previous research conclusions, the optimum pyrolysis temperature of Desmodesmus sp. EJ 8-10 was approximately $600^{\circ} \mathrm{C}^{[14]}$. The pyrolysis products were monitored and analyzed in real time by Curie-point pyrolyzer-gas chromatography/mass spectrometry (Py-GC/MS). By comparing the NIST 2011 spectra library data (Version 2.0, National Institute of Science and Technology, USA), the composition and relative content of the pyrolysis products were obtained. According to the characteristics of Py-GC/MS instrument, the following assumptions were made:

(1) Since Desmodesmus sp. EJ 8-10 was instantaneously pyrolyzed in the pyrolyzer, the instantaneous energy consumption was neglected.

(2) The energy transfer inside the pyrolyzer was neglected.

(3) Since the proportion of the pyrolysis time in the life of the pyrolysis device was very small, the maintenance of the device was neglected.

(4) The on-line analysis of pyrolysis products only considered the energy consumed in the whole process after the pyrolysis products enter the GC/MS instrument, which was separated by the programmed temperature and detected by mass spectrometry in real time.

Other energy consumption factors were neglected. According to the previous research results, it took $50 \mathrm{~min}$ for temperature-programmed heating, and the pyrolysis product analysis consumed around $2.2 \mathrm{~kW} \cdot \mathrm{h}$.

During the pyrolysis stage of Desmodesmus sp. EJ 8-10 at $600^{\circ} \mathrm{C}$, it took $10.8 \mathrm{~min}$ for the chamber temperature inside the pyrolyzer to increase from room temperature $\left(25.6^{\circ} \mathrm{C}\right)$ to the optimal temperature $\left(600^{\circ} \mathrm{C}\right)$. The pyrolysis of $1 \mathrm{~kg}$ Desmodesmus sp. EJ 8-10 consumed $720 \mathrm{~kW} \cdot \mathrm{h}$ of electricity. The energy consumption during the pyrolysis stage of Desmodesmus sp. EJ 8-10 was $722.2 \mathrm{~kW} \cdot \mathrm{h}$, and the main gas emission was $\mathrm{CO}_{2}$ (Table 2).

\section{Impact assessment}

\subsection{Energy efficiency analysis}

As shown in Table 3, the energy consumption of Desmodesmus sp. EJ 8-10 throughout the life cycle was 17489.9 MJ. In the entire life cycle of these three stages, the energy consumption in the harvest stage was the highest, up to $56.24 \%$, followed by the pyrolysis stage, and the lowest was the cultivation stage.

Table 3 Life cycle energy consumption of Desmodesmus sp. EJ 8-10 pyrolysis process

\begin{tabular}{ccc}
\hline Stage & Energy consumption/MJ & Percentage/\% \\
\hline Cultivation & 1862.2 & 10.65 \\
Harvest & 9835.7 & 56.24 \\
Prolysis & 5792.0 & 33.12 \\
Sum & 17489.9 & 100.01 \\
\hline
\end{tabular}

In this study, the High Heating Value (HHV) Equation was used to calculate the energy of the pyrolysis products ${ }^{[24]}$ To facilitate the research and data calculations, the following assumptions were made:

(1) The pyrolysis products with larger peak areas and stable detection results were summarized and compared, and the pyrolysis products with matching degrees greater than $80 \%$ were studied.

(2) In the process of calculating HHV of pyrolysis products, the relative content of the pyrolysis products was determined by using the area normalization method, the chemical formula (a) was determined according to the chemical abstracts service number (CAS No.) of each pyrolysis product, and a new chemical formula (b) was obtained by multiplying the atomic number of the elements in the chemical formula of each pyrolysis product by the relative content of each component, according to the principle of the addition of the atomic number of the same element. All pyrolysis products were combined to fit into a new empirical chemical formula (c), namely, $\mathrm{C}_{x} \mathrm{H}_{y} \mathrm{O}_{z} \mathrm{~N}_{i} \mathrm{~S}_{m}$.

According to previous research, the pyrolysis products of Desmodesmus sp. EJ 8-10 at $600^{\circ} \mathrm{C}$ (the matching degree was more than $80 \%$ ) are shown in Table 4 . According to the above steps, a new chemical formula for fitting the pyrolysis products of EJ 8-10 at $600^{\circ} \mathrm{C}$ was $\mathrm{C}_{672.31} \mathrm{H}_{1150.67} \mathrm{O}_{18.72} \mathrm{~N}_{5.79} \mathrm{~S}_{0}$, and the $\mathrm{HHV}$ was considered to be $38512.67 \mathrm{MJ} / \mathrm{kg}$.

The energy conversion efficiency $\eta$ was calculated as Equation (1):

$$
\eta=q_{\text {pyrolysis products }} / L C A_{\text {energy }}
$$

where, $\eta$ is the energy conversion efficiency; $q_{\text {pyrolysis products }}$ is the $\mathrm{HHV}$ of the pyrolysis products; $L C A_{\text {energy }}$ is the energy consumption in the life cycle.

The $\eta$ of Desmodesmus sp. EJ 8-10 was 2.2, greater than 1, which indicated that the pyrolysis process of Desmodesmus sp. EJ 8-10 was beneficial.

Table 4 Identification and quantification of chemical compounds from Desmodesmus sp. EJ 8-10 pyrolyzed at $600^{\circ} \mathrm{C}$ (Qual $>\mathbf{8 0 \%}$ )

\begin{tabular}{|c|c|c|}
\hline Groups & Compounds & $\begin{array}{l}\text { Relative } \\
\text { content } / \%\end{array}$ \\
\hline \multirow{9}{*}{ Alkanes } & Cyclopropane, octyl- & 0.81 \\
\hline & cis-1-Butyl-2-methyl cyclopropane & 0.71 \\
\hline & cis-1-Hexyl-2-propyl cyclopropane & 1.07 \\
\hline & Cyclododecane & 0.75 \\
\hline & $\begin{array}{l}(7 \mathrm{R}, 8 \mathrm{~S}) \text {-cis-anti-cis-7,8-Epoxytri } \\
\text { cyclo[7.3.0.0(2,6)] dodecane }\end{array}$ & 0.42 \\
\hline & Pentadecane & 0.28 \\
\hline & Cyclopentadecane & 2.50 \\
\hline & Cyclohexadecane, 1,2-diethyl- & 1.08 \\
\hline & Heptadecane & 1.29 \\
\hline \multirow{16}{*}{ Olefins } & E,Z-4-Ethylidene cyclohexene & 0.11 \\
\hline & 1,4-Cyclohexadienen & 0.23 \\
\hline & 1-Heptene & 0.71 \\
\hline & 1,4-Cyclooctadiene & 0.49 \\
\hline & Bicyclo[4.2.0]octa-1,3,5-triene & 0.24 \\
\hline & 1-Nonene & 0.43 \\
\hline & 1-Decene & 0.64 \\
\hline & 1-Tridecene & 0.55 \\
\hline & 1-Tetradecene & 0.80 \\
\hline & 1-Pentadecene & 1.15 \\
\hline & 2-Hexadecene, 2,6,10,14-tetramethyl- & 0.74 \\
\hline & 2-Hexadecene, 3,7,11,15-tetramethyl- & 1.60 \\
\hline & 1-Heptadecene & 0.36 \\
\hline & 3-Heptadecene, (Z)- & 0.29 \\
\hline & 1-Octadecene & 0.24 \\
\hline & 1-Nonadecene & 4.82 \\
\hline \multirow{3}{*}{ Fatty acids } & n-Hexadecanoic acid & 3.23 \\
\hline & 9-Hexadecenoic acid & 0.69 \\
\hline & Oleic acid & 1.71 \\
\hline
\end{tabular}




\begin{tabular}{|c|c|c|}
\hline Groups & Compounds & $\begin{array}{l}\text { Relative } \\
\text { content } / \%\end{array}$ \\
\hline \multirow{7}{*}{$\begin{array}{l}\text { Nitrogen- } \\
\text { containing } \\
\text { compounds }\end{array}$} & Benzyl nitrile & 0.98 \\
\hline & Indole & 2.20 \\
\hline & 3-Methyl-1 $H$-indole & 1.55 \\
\hline & Pyridine & 0.50 \\
\hline & Pyridine, 2-methyl- & 0.13 \\
\hline & Pyridine, 3-methyl- & 0.18 \\
\hline & Pyridine, 3,5-dimethyl- & 0.25 \\
\hline Phenols & Phenol, 4-methyl- & 2.86 \\
\hline \multirow{5}{*}{ PAHs } & 1,3-Dimethylnaphthalene, & 0.42 \\
\hline & 2,6-Dimethylnaphthalene, & 0.21 \\
\hline & 1,2-Dihydro-1,1,6-trimethyl Naphthalene & 0.53 \\
\hline & 1,2,3,4-Tetrahydro-1,1,6-Trimethylnaphthalene & 0.67 \\
\hline & $\begin{array}{l}\text { Octahydro-4a-methyl-7-(1-methyl)- } \\
\text { 2(1H)-naphthalenone }\end{array}$ & 0.12 \\
\hline \multirow{4}{*}{$\begin{array}{l}\text { Carbonyls and } \\
\text { alcohols }\end{array}$} & 3,7,11-Trimethyl-2,6,10 -dodecatrien-1-ol & 0.13 \\
\hline & 3-Methylbutanal & 0.59 \\
\hline & 2-Octylcyclopropaneoctanal & 0.11 \\
\hline & 7,11-Hexadecadienal & 1.13 \\
\hline \multirow{4}{*}{ Furans } & 2,5-Dimethylfuran & 0.36 \\
\hline & 3-Dodecyl-2,5-Furandione & 0.58 \\
\hline & Methyl 7,10-hexadecadienoate & 0.03 \\
\hline & 2-Dodecen-1-yl(-)succinic anhydride & 0.64 \\
\hline
\end{tabular}

\subsection{Environmental impact load}

\subsubsection{Calculation of the environmental impact potential}

The environmental impact potential of the products refers to the sum of all environmental emission impacts (including resource consumption) in the whole product system, which can be expressed by the following formula:

$$
E P(j)=\sum E P(j)_{i}=\sum\left[Q(j)_{i} \times E F(j)_{i}\right]
$$

where, $E P(j)$ is the contribution of the research system to the $j$ th potential environmental influence; $E P(j)_{i}$ is the contribution of the $i$ th emission substance to the $j$ th potential environment; $Q_{i}$ is the discharge amount of the $i$ th substance; $E F(j)_{i}$ is the equivalent factor of the $i$ th emission substance to the potential environmental influence ${ }^{[25-27]}$.

There were four types of environmental impacts analyzed in this study, followed by global warming, acidification, photochemical ozone synthesis and eutrophication ${ }^{[28-30]}$. Table 5 shows the environmental impact potential analysis of the Desmodesmus sp. EJ 8-10 pyrolysis life cycle. First, the global warming potential of the Desmodesmus sp. EJ 8-10 pyrolysis life cycle was $2423.799 \mathrm{~kg} \mathrm{CO}$ eq, where $\mathrm{CO}_{2}$ was the main influencing factor, up to $65.31 \%$; $\mathrm{NO}_{\mathrm{x}}$ emission $(31.25 \%)$ was the second, followed by $\mathrm{CH}_{4}$ and $\mathrm{CO}$. The acidification potential of Desmodesmus sp. EJ 8-10 was $4.196 \mathrm{~kg} \mathrm{SO}_{2} \mathrm{eq}$; the main substances affected were $\mathrm{SO}_{2}$ and $\mathrm{NO}_{\mathrm{x}}$, among which the contribution of $\mathrm{SO}_{2}$ to acidification was slightly higher than $\mathrm{NO}_{\mathrm{x}}$. The photochemical ozone synthesis potential of Desmodesmus sp. EJ 8-10 was $0.23046 \mathrm{~kg} \mathrm{CO}_{2} \mathrm{eq}$, which $\mathrm{CO}$ emission was considered as its biggest share $(65.34 \%)$, and the contribution of VOC was slightly higher than that of $\mathrm{CH}_{4}$. In the eutrophication potential analysis of Desmodesmus sp. EJ 8-10, eutrophication was caused entirely by $\mathrm{NO}_{\mathrm{x}}$ emissions $(0.3176 \mathrm{~kg} \mathrm{PO}$ eq).
Table 5 Analysis on potential environmental impact of pyrolysis process of Desmodesmus sp. EJ 8-10

\begin{tabular}{|c|c|c|c|c|c|}
\hline Impact category & \multicolumn{5}{|c|}{ Desmodesmus sp. EJ 8-10 } \\
\hline \multirow{5}{*}{$\begin{array}{c}\text { Global } \\
\text { warming }\end{array}$} & Substance & $\mathrm{CO}_{2}$ & $\mathrm{CH}_{4}$ & $\mathrm{NO}_{\mathrm{x}}$ & $\mathrm{CO}$ \\
\hline & Effect equivalent factor & 1 & 21 & 310 & 2 \\
\hline & Quantity/kg & 1583.04 & 3.925 & 2.443 & 0.502 \\
\hline & $\mathrm{Sum} / \mathrm{kg} \mathrm{CO}$ eq & 1583.04 & 82.425 & 757.33 & 1.004 \\
\hline & Proportion/\% & 65.31 & 3.40 & 31.25 & 0.041 \\
\hline \multirow{5}{*}{ Acidification } & Substance & \multicolumn{2}{|c|}{$\mathrm{SO}_{2}$} & \multicolumn{2}{|c|}{$\mathrm{NO}_{\mathrm{x}}$} \\
\hline & Effect equivalent factor & \multicolumn{2}{|c|}{1} & \multicolumn{2}{|c|}{0.7} \\
\hline & Quantity/kg & \multicolumn{2}{|c|}{2.486} & \multicolumn{2}{|c|}{2.443} \\
\hline & $\mathrm{Sum} / \mathrm{kg} \mathrm{SO} \mathrm{SO}_{2}$ & \multicolumn{2}{|c|}{2.486} & \multicolumn{2}{|c|}{1.71} \\
\hline & Proportion/\% & \multicolumn{2}{|c|}{59.25} & \multicolumn{2}{|c|}{40.75} \\
\hline \multirow{5}{*}{$\begin{array}{l}\text { Photochemical } \\
\text { ozone formation }\end{array}$} & Substance & VOC & $\mathrm{CO}$ & \multicolumn{2}{|c|}{$\mathrm{CH}_{4}$} \\
\hline & Effect equivalent factor & 0.6 & 0.3 & \multicolumn{2}{|c|}{0.007} \\
\hline & Quantity/kg & 0.0873 & 0.502 & \multicolumn{2}{|c|}{3.925} \\
\hline & $\mathrm{Sum} / \mathrm{kg} \mathrm{CO} \mathrm{CO}_{2}$ eq & 0.05238 & 0.1506 & \multicolumn{2}{|c|}{0.02748} \\
\hline & Proportion/\% & 22.73 & 65.34 & \multicolumn{2}{|c|}{11.92} \\
\hline \multirow{5}{*}{ Eutrophication } & Substance & \multicolumn{4}{|c|}{$\mathrm{NO}_{\mathrm{x}}$} \\
\hline & Effect equivalent factor & \multicolumn{4}{|c|}{0.13} \\
\hline & Quantity/kg & \multicolumn{4}{|c|}{2.443} \\
\hline & $\mathrm{Sum} / \mathrm{kg} \mathrm{PO}_{4} \mathrm{eq}$ & \multicolumn{4}{|c|}{0.3176} \\
\hline & Proportion/\% & \multicolumn{4}{|c|}{100} \\
\hline
\end{tabular}

4.2.2 Standardization of the environmental impact potential

Although the types of environmental impacts and the equivalent factors have been determined, the environmental impact potential needs to be standardized for evaluating. The standardization process is primarily to establish a standardized benchmark, then provide a comparable standard for the relative size of the various types of impact. The formula for data standardization in inventory analysis is shown as followed:

$$
N P(j)=P(j) \times \frac{1}{T \cdot R(j)}
$$

where, $T$ is the product service period; $R(j)$ is the standard benchmark for the $j$ th year; $P(j)$ are the various environmental influence potentials or resource consumption ${ }^{[28]}$. In this system, all depreciations and losses were neglected. Therefore, in this study, $T$ was $1^{[26]}$. The formula for data standardization of the inventory analysis can be simplified to:

$$
N P(j)=P(j) \times \frac{1}{R(j)}
$$

In this study, the year 2000 was selected as the reference year. According to Equation (4), the environmental impact potential of the standardized Desmodesmus sp. EJ 8-10 pyrolysis was calculated and listed in Table $6^{[31]}$. The standardized environmental impact potential unit was the standard person equivalent $(\mathrm{PE})$, which was the average environmental impact potential per person per year ${ }^{[32]}$.

Among the four environmental impact types evaluated (Table 6), the Desmodesmus sp. EJ 8-10 pyrolysis process had the greatest impact on global warming, reaching $58.14 \%$. Then, the eutrophication and acidification processes accounted for $27.54 \%$ and $13.23 \%$, respectively. The least influential factor was photochemical ozone synthesis, which accounted for only $1.09 \%$ of the total. The analysis of the proportion of impact types after standardization was in the following sequence: global warming > eutrophication $>$ acidification $>$ photochemical ozone synthesis. 
Table 6 Normalized environmental impact potentials of Desmodesmus sp. EJ 8-10 pyrolysis process

\begin{tabular}{lccc}
\hline \multicolumn{1}{c}{ Impact category } & Quantity & Standardized reference value & Standardized potential \\
\hline Global warming & $2423.799 \mathrm{~kg} \mathrm{CO}_{2} \mathrm{eq} / \mathrm{kg}$ & $6869 \mathrm{~kg} \mathrm{CO}_{2}$ & $352.86 \mathrm{mPE}$ \\
Acidification & $4.196 \mathrm{~kg} \mathrm{SO}_{2} \mathrm{eq} / \mathrm{kg}$ & $52.26 \mathrm{~kg} \mathrm{SO}_{2}$ & $50.29 \mathrm{mPE}$ \\
Eutrophication & $0.3176 \mathrm{~kg} \mathrm{PO}_{4} \mathrm{eq} / \mathrm{kg}$ & $1.9 \mathrm{~kg} \mathrm{PO}_{4}$ & 13.23 \\
Photochemical Ozone synthesis & $0.2305 \mathrm{~kg} \mathrm{C}_{2} \mathrm{H}_{4} \mathrm{eq} / \mathrm{kg}$ & $34.72 \mathrm{~kg} \mathrm{C}_{2} \mathrm{H}_{4}$ & 27.54 \\
\hline
\end{tabular}

4.2.3 Weighted assessment and environmental impact load

The standardized data only show the relative size of the potential environmental impact. Even if different types of environmental impact potentials have the same impact potentials via standardization, it does not mean that their potential impact on the environment is equally serious. Therefore, it is necessary to synthesize all kinds of environmental impact composite indexes to obtain the environmental impact composite index and provide a comparable evaluation result, that is, assign different weights to different environmental impact types. The severity of the different types of environmental impact was ranked to distinguish the magnitude of their environmental impact hazards.

$$
W P(j)=W F(j) \times N P(j)=W F(j) \cdot \frac{1}{T \cdot R(j)} \cdot P(j)
$$

where, $W F(j)$ is the weight factor of the $j$ th environmental impact and $N P(j)$ is the impacted potential after standardization ${ }^{[25]}$.

In this study, the target distance method was used to determine the weighting factor ${ }^{[30]}$. The formula is as follows:

$$
W F(j)=\frac{E R(j)_{90}}{E R(j)_{T 2000}}
$$

where, $E R(j)_{90}$ is the total of the global or regional environmental impact potential in 1990 and $E R(j)_{T 2000}$ is the total of the global or regional environmental impact potential in $2000^{[26,27]}$.

The weighted environmental impact potentials reflect their relative importance and are comparable. The various environmental potentials can also be obtained by comparison. Therefore, the potential value of the environmental impact types is integrated to obtain a single index for comparison, called the environmental impact load (EIL), which reflects the environmental impact of the research system during the whole life cycle. The formula is as follows:

$$
E I L=\sum W P(j)=\frac{E R(j)_{90}}{E R(j)_{T 2000}} \times \frac{E P(j)}{E R(j)_{90}}=\sum\left[\frac{\sum Q(j)_{i} \times E F(j)_{i}}{E R(j)_{T 2000}}\right]
$$

where, $W P(j)$ is the type of weighted environmental impact; $Q i$ is the emission of substance $i ; E F(j)_{i}$ is the equivalent factor for the potential environmental impact $i$ of the emission substance $j$; $E R(j)_{T 2000}$ is the benchmark of the environmental impact potential in 2000 .

The environmental impact potentials of Desmodesmus sp. EJ 8-10 were weighted; the standardized result was multiplied by the corresponding weighting factor and then added to obtain the total EIL. The results are shown in Table $7^{[32]}$. After weighting, the total EIL of the $1 \mathrm{~kg}$ Desmodesmus sp. EJ 8-10 pyrolysis process in its life cycle was $1165.67 \mathrm{mPE}_{\mathrm{T} 2000}$. Among them, the main impact on the environment was eutrophication, accounting for $57.36 \%$, followed by photochemical ozone synthesis and acidification, accounting for $22.56 \%$ and $17.36 \%$, respectively; the

\begin{tabular}{|c|c|c|c|c|}
\hline Impact category & Standardized value/mPE $\mathrm{T}_{\mathrm{T} 2000}$ & Weight factor & Weighted value/mPE $\mathrm{T}_{\mathrm{T} 2000}$ & Proportion/\% \\
\hline Global warming & 352.86 & 0.09 & 31.76 & 2.73 \\
\hline Acidification & 80.29 & 2.52 & 202.33 & 17.36 \\
\hline Eutrophication & 167.16 & 4 & 668.64 & 57.36 \\
\hline Photochemical ozone synthesis & 6.64 & 39.6 & 262.94 & 22.56 \\
\hline
\end{tabular}
global warming impact only accounted for $2.73 \%$.

Table 7 Desmodesmus sp. EJ 8-10 valued EP of the environmental impact potentials

\section{Conclusions}

The energy consumption of the Desmodesmus sp. EJ 8-10 throughout its life cycle was 17489.9 MJ. The analysis of the energy consumption resulted in the following sequence: the microalgae harvest stage $>$ pyrolysis stage $>$ cultivation stage. The energy conversion efficiency $\eta$ of the entire pyrolysis process of Desmodesmus sp. EJ 8-10 was 2.2 (greater than 1), which indicated that the entire pyrolysis process was beneficial. The whole life cycle environmental impact of EJ 8-10 was 1165.67 $\mathrm{mPE}_{\mathrm{T} 2000}$. Among the environmental factors, eutrophication (57.36\%), photochemical ozone synthesis $(22.56 \%)$, acidification $(17.36 \%)$ and global warming $(2.73 \%)$ exhibited the major impact. Therefore, the biofuel production from microalgae combined with wastewater treatment could be recommended as a promising way.

\section{Acknowledgements}

This research was supported by the Beijing Municipal Natural Science Fund-Key project of science and technology plan of Beijing Education Committee (KZ201810011017); Beijing
Municipal Education Commission General Project (KM201810011002); Chinese National 13th five-year Plan for Key R \& D Projects (2018YFD0400804); the National Natural Science Foundation of China (Grant No. 51806242 and No. 41942006); Public Opening Project of the Key Laboratory of Development and Application of Rural Renewable Energy, Ministry of Agriculture, China (Grant No. 2017008); the Chinese Universities Scientific Fund (Grant No. 2019TC010); and the Chinese Universities Scientific Fund - Special Project for "Double First-Class" Initiative of College of Engineering - Agricultural Mechanization and Equipment Engineering, China Agricultural University. We also appreciate for the supports from Beijing Municipal Key Discipline of Biomass Engineering.

\section{[References]}

[1] Li G, Xiang S N, Ji F, Zhou Y G, Huang Z G. Thermal cracking products and bio-oil production from microalgae Desmodesmus sp. Inter Agric \& Biol Eng, 2017; 10(4): 198-206.

[2] Marjakangas J M, Chen C Y, Lakaniemi A M, Puhakka J A, Whang L M, Chang J S. Simultaneous nutrient removal and lipid production with Chlorella vulgaris on sterilized and non-sterilized anaerobically pretreated 
piggery wastewater. Biochemical Engineering Journal, 2015; 103: 177-184.

[3] Li G, Bai X, Li H, Lu Z T, Zhou Y G, Wang Y K, et al. Nutrients removal and biomass production from anaerobic digested effluent by microalgae: A review. Inter Agric \& Biol Eng, 2019; 12(5): 8-13.

[4] Chang H X, Fu Q, Huang Y, Xia A, Liao Q, Zhu X. Improvement of microalgae lipid productivity and quality in an ion-exchange-membrane photobioreactor using real municipal wastewater. Inter Agric \& Biol Eng, 2017; 10(1): 97-106

[5] Ji F, Liu Y, Hao R, Li G, Zhou Y G, Dong R J. Biomass production and nutrients removal by a new microalgae strain Desmodesmus sp. in anaerobic digestion wastewater. Bioresource Technology, 2014; 161: 200-207.

[6] Eltanahy E, Salim S, Vadiveloo A, Verduin J, Pais B, Moheimani N. Comparison between jet and paddlewheel mixing for the cultivation of microalgae in anaerobic digestate of piggery effluent (ADPE). Algal Research, 2018; 35: 274-282.

[7] Chang X M, Yao X L, Ding N, Ying X F, Zheng Q M, Lu S L, et al. Photocatalytic degradation of trihalomethanes and haloacetonitriles on graphitic carbon nitril under visible light irradiation. Sci Total Environ, 2019; 682: 200-207.

[8] Lu Q, Yang X C, Dong C Q, Zhang Z F, Zhang X M, Zhu X F. Influence of pyrolysis temperature and time on the cellulose fast pyrolysis products: Analytical Py-GC/MS study. Journal of Analytical and Applied Pyrolysis, 2011; 92 (2): 430-438.

[9] Liu Y, Yao X L, Wang Z B, Li H L, Shen X B, Yao Z L, et al. Synthesis of activated carbon from critic acid residue by phosphoric acid activation for the removal of chemical oxygen demand from sugar-containing wastewater. Environ Eng Sci, 2019; 36: 6. DOI: 10.1089/ees.2018.0506.

[10] Li G, Ji F, Bai X, Zhou Y G, Dong R J, Huang Z G. Comparative study on thermal cracking characteristics and bio-oil production from different microalgae using by Py-GC/MS. Inter Agric \& Biol Eng, 2019; 12(1): 208-213.

[11] Arun J, Varshini P, Prithvinath P K, Priyadarshini V, Gopinath K P. Enrichment of bio-oil after hydrothermal liquefaction (HTL) of microalgae C. vulgaris grown in wastewater: Bio-char and post HTL wastewater utilization studies. Bioresource Technology, 2018; 261: 182-187.

[12] Wang Z H, Adhikari S, Valdez P, Shakya R, Laird C. Upgrading of hydrothermal liquefaction biocrude from algae grown in municipal wastewater. Fuel processing Technology, 2016: 142: 147-156.

[13] Lee J K, Sohn D H, Lee K Y, Park K Y. Solid fuel production through hydrothermal carbonization of sewage sludge and microalgae Chlorella sp. from wastewater treatment plant. Chemosphere, 2019; 230: 157-163.

[14] Li G, Dong R J, Fu N, Zhou Y G, Li D, Chen X D. Characterization of pyrolysis products obtained from Desmodesmus sp. cultivated in anaerobic digested effluents (DADE). International Journal of Food Engineering, 2015; 11(6): 825-831.

[15] Xin C H, Addy M M, Zhao J Y, Chen Y L, Ma Y W, Liu S Y et al. Waste-to-biofuel integrated system and its comprehensive techno-economic assessment in wastewater treatment plants. Bioresource Technology, 2018; 250: 523-531.

[16] Quinteiro P, Tarelho L, Marques P, Martin-Gamboa M, Freire F, Arroja L, et al. Life cycle assessment of wood pellets and wood split logs for residential heating. Science of the Total Environment, 2019; 689:
$580-589$.

[17] Arashio L T, Montero N, Ferrer I, Acién F G, Gómez C, Garfí M. Life cycle assessment of high rate algal ponds for wastewater treatment and resource recovery. Science of the Total Environment, 2018; 622-623: 1118-1130.

[18] Lee K, Inaba A. Life cycle assessment best practices of ISO 14040 series Center for Ecodesign and LCA (CEL), Ajou University, 2004.

[19] ISO14043: Environmental management-life cycle assessment-life cycle interpretation, 2000 (E).

[20] Morales M, Quintero J, Conejeros R, Aroca G. Life cycle assessment lignocellulosic bioethanol: Environmental impacts and energy balance. Renewable Sustainable Energy Review, 2015; 42: 1349-1361.

[21] Ubando A T, Rivera D R T, Chen W H, Culaba A B. A comprehensive review of life cycle assessment (LCA) of microalgal and lignocellulosic bioenergy products from thermochemical processes. Bioresource Technology, 2019; 291: 12183.

[22] Marsmann M. The ISO 14040 family. International Journal of Life Cycle Assessment, 2000; 5(6): 317-318.

[23] Li G, Ji F, Zhou Y G, Dong R J. Life cycle assessment of pyrolysis process of Desmodesmus sp. Inter Agric \& Biol Eng, 2015; 8(5): $105-112$.

[24] Mahinpey N, Murugan P, Mani T, Raina R. Analysis of bio-oil, biogas, and biochar from pressurized pyrolysis of wheat straw using a tubular reactor. Energy Fuels, 2009; 23(5): 2736-2742.

[25] Liu Y X, Langer V, Hogh-Jensen H, Egelyng H. Life cycle assessment of fossil energy use and greenhouse gas emissions in Chinese pear production. Journal of Clean Production, 2010; 18(14): 1423-1430.

[26] Liu J, Ma X Q. The analysis on energy and environmental impacts of microalgae-based fuel methanol in China. Energy Policy, 2009; 37(4): 1479-1488.

[27] Wang H R, Xu J L, Yang X F, Miao Z, Yu C. Organic rankine cycle saves energy and reduces gas emissions for cement production. Energy, 2015; 86: 59-73.

[28] Houghton J T. (Ed.). Climate change 1995: The science of climate change: contributing of working group 1 to the second assessment report of the intergovernmental panel on climate change. Cambridge University Press, 1996.

[29] Brentrup F, Küsters J, Kuhlmann H, Lammel J. Environmental impact assessment of agricultural production systems using the life cycle assessment methodology: I. Theoretical concept of a LCA method tailored to crop production. European Journal of Agronomy, 2004; 20(3): 247-264.

[30] Wang M X, Bao Y H, Wu W L, Liu W N. Life cycle environmental impact assessment of winter in north China plain. Journal of Agro-Environment Science, 2006; 25(5): 1127-1132.

[31] Sleeswijk A W, van Oers L F C M, Guinée J B, Struijs J, Huijbregts M A J. Normalisation in product life cycle assessment: An LCA of the global and European economic systems in the year 2000. Science of the Total Environment, 2008; 390(1): 227-240.

[32] Huang C L. Life cycle assessment (LCA) for the product of synthesized polymer biomedical material. Master Dissertation. Sichuan: Southwest Jiaotong University, 2004. (in Chinese)

[33] Finnveden G, Hauschild M Z, Ekvall T, GuinéeJ, Heijungs R, Hellweg S, et al. Recent developments in life cycle assessment. Journal of Environmental Management, 2009; 91(1): 1-21. 